\title{
Novel Five-Phase Permanent Magnet Generator Systems for Wind Turbine Applications
}

\author{
M. T. Mohammad ${ }^{1}$, J. E. Fletcher ${ }^{1}$, and N. A. Hassanain ${ }^{1}$ \\ ${ }^{1}$ Department of Electronic and Electrical Engineering \\ University of Strathclyde \\ 204 George Street, Glasgow, G1 1XW, UK \\ Phone number: +0044 1415482949, e-mail: m.mohammad@eee.strath.ac.uk
}

\begin{abstract}
.
This paper discusses the benefits of five-phase technology for applications including wind turbine generators. The performances of three-phase and five-phase permanent magnet generator (PMG) systems that use diode rectifier circuits are discussed. Investigations proved that the five-phase topology harnesses some specific and important benefits that are not provided by three-phase systems. The benefits include improved fault tolerance and reliability, and reduced voltage and torque ripple and size of DC link capacitor. These are general improvements that are sought after in many applications including renewable energy applications. The paper also discusses the design of a novel five-phase wind turbine generator which was optimised to make use of the key competitive advantages of our five-phase technology in renewable energy sector. Finite element (FE) and Matlab / Simulink are used in the investigations. Test results are also presented in this paper and used to validate simulations where possible.
\end{abstract}

\section{Key words}

Wind turbine generators, multi-phase machines, permanent-magnet dc machines.

\section{Introduction}

Multi-phase machine technology typically refers to machines with phase number greater than three. Traditionally, electrical energy has been generated by large-scale power stations using three-phase synchronous generators. Bulk electrical energy is therefore transmitted and distributed using three-phase lines and cables. Users of electrical energy then must use three-phase electrical machines to allow easy connection to the three-phase supplies that are provided by distribution networks. Hence three-phase machines have become the industry standard and the workhorse of electromechanical conversion.

However, the choice of using three-phase is arbitrary in many systems. For example, in inverter based systems the input DC voltage can be converted to any number of phase outputs, not just three phases. This has lead to the concept of multi-phase technology where multi-phase machines can operate with five phases instead of three. Five-phase machines can also employ permanent magnet excitation, which removes the need to set up and control the magnetic field in the machine.

The driver for adopting the five-phase technology is that it harnesses some specific and important benefits that are not provided by traditional three-phase systems especially for renewable energy applications such as wind turbine generators [1]. This includes improved torque density, efficiency and fault tolerance, and reduced torque ripple and dc-link energy storage [1-4]. In addition, they also can be designed with partially pitched windings, allowing a degree of shaping of the voltage waveforms. The combinations of multi-phase technology, permanent magnets and partially pitched windings provides improvements in performance, and optimised designs to make it suitable for use with diode rectifier circuits which predominate in small and medium scale generation. Such systems are particularly suited to small and medium scale wind turbines.

\section{Description of Two Generator Systems}

To investigate the benefits of using five-phase technology for wind turbine applications, a three-phase and a five-phase dc generator systems were designed and built for small-scale applications. Two generators were designed to give the same output power and speed of 750 $\mathrm{W}$, and $1400 \mathrm{rpm}$ respectively. They also have the same topology and dimensions of stator and rotor where each rotor and stator has 4 magnet poles and 30 slots respectively. The generators have a stack length of 50 $\mathrm{mm}$ and a stator OD of $120 \mathrm{~mm}$ where the rotor/stator ratio is 0.6. The difference between the two designs is the windings which were arranged to have three and five phases with different coil spans. In addition, both generators have fractional slots with double-layer windings because the number of slots per pole is not integer and consequently each slot has two coils of different phases.

Different methods to design fractional-slot windings, five-phase machines are described in [2-4]. However, the novel winding arrangements of the two machines under 
investigation were designed to take advantages of two known techniques. The first technique described in [5] gives general results for double-layer windings, which tends to minimize the build-up of phase displacement. In the method, the layout for double-layer lap winding depends on coil angle and location. The second technique described in [6] determines the distribution factor based on the arrangements of two sets of pole-groups. Our winding configuration combines these two methods; it simplifies the winding configuration, and gives better results for double-layer windings, allowing improved shaping of the voltage waveforms.

The system configuration of both three-phase and fivephase generator systems consists of a DC permanent magnet generator, a diode bridge rectifier, smoothing capacitor $(470 \mu \mathrm{F})$ and a resistive load. Figure 1 shows the configuration of the generators and their associated rectifier systems. Similar rectifier systems are described in [7-10]

Both generators are designed to have equal values of load voltages, current densities in the coils, output power, and rated speed where the values of load resistances can be adjusted.

FE analysis was performed to optimise the design and keep flux densities within accepted levels. Figure 2 shows the densities and distribution of the flux in a cross section of the generator in no-load conditions.
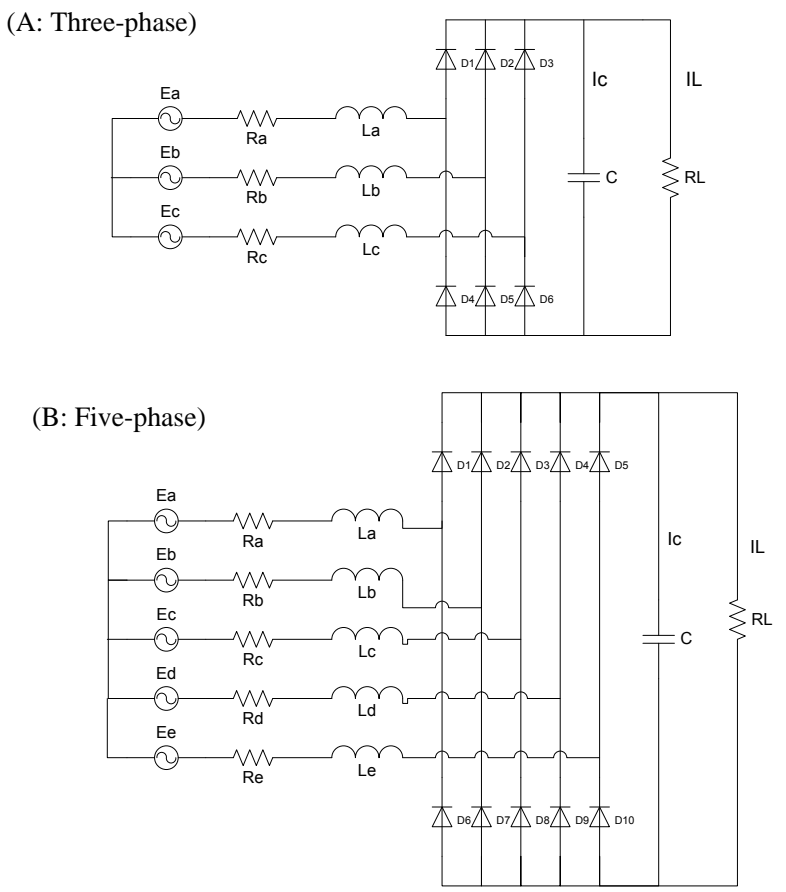

Figure 1: Schematic diagram of the three-phase and five-phase PMGs with rectifier systems.

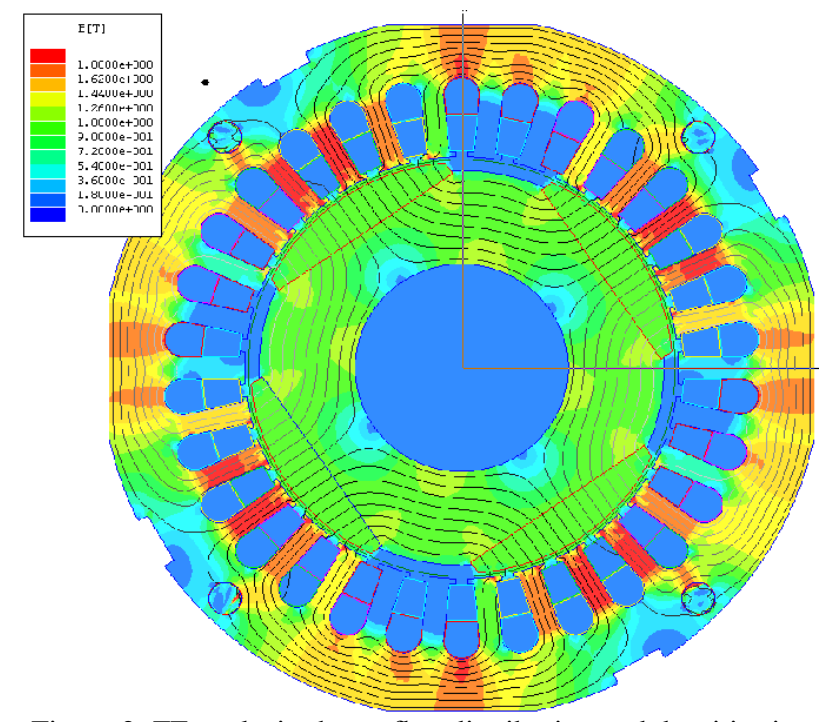

Figure 2: FE analysis shows flux distribution and densities in a cross-section of the generator.

\section{Basic Five-Phase Theoretical System Analysis}

One of the main advantages of the five-phase systems comes from the fact that the output dc voltage (at the dc link side) has a fundamental frequency of ten times the input frequency and a peak value of $1.902 \mathrm{~V}_{\mathrm{m}}$ as shown in figure 3. This has significant impact in reducing the ripple torque as we will see later in the test results. In three-phase systems the output dc voltage is six times the input frequency and consequently more ripples at the $\mathrm{dc}$ link side than their equivalent five-phase systems.

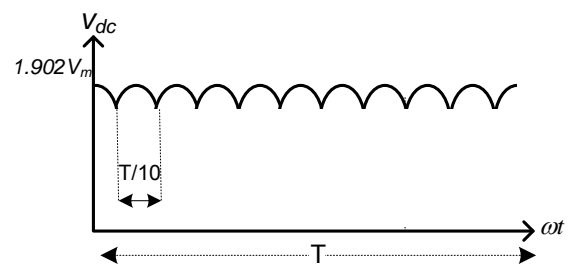

Figure 3: The output voltage from a five-phase rectifier.

\section{A. Voltages}

The five-phase circuit shown in figure 1 has a five-phase generator that feeds a five-phase full-bridge diode rectifier. Ignoring commutation, each diode of the rectifier would conduct the full-load current for $72^{\circ}$ in the ideal case. The five-phase generator produces five-phase line voltages where the adjacent phases are shifted by $72^{\circ}$ from each other.

The five-phase system has adjacent and non-adjacent line voltages as shown in figure 4 . These voltages can be calculated as follows [11].

$$
\begin{aligned}
& V_{\text {line }, \text { adjacent }}=2 V_{p h} \cos \left(54^{\circ}\right)=1.176 \times V_{p h} \\
& V_{\text {line, } \text { non-adjacent }}=2 V_{p h} \cos \left(18^{\circ}\right)=1.902 \times V_{p h} \\
& V_{\text {line,non-adjacent }}=1.618 V_{\text {line,adjacent }}
\end{aligned}
$$




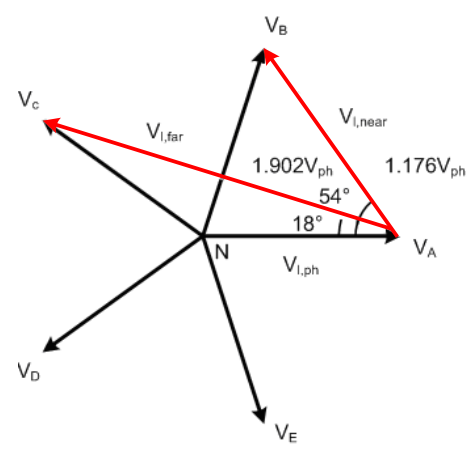

Figure 4: Phasor diagram shows the adjacent and non-adjacent line voltages of the five-phase system.

\section{B. Capacitors}

A smoothing capacitor is often connected in parallel with the load to generate a constant DC-link voltage. The total dc current, $I_{d c}$ at the DC link side is the total of the load current, $I_{L}$, and the capacitor current, $I_{C}$ :

$$
I_{d c}=I_{c}+I_{L}
$$

The capacitor current can be calculated as follows [11]:

$$
I_{c}=1.902 V_{m} \omega C Q .9511 \cos (\omega t)-0.31 \sin (\omega t)
$$

Where,

$$
\frac{\pi}{10} \leq \omega \mathrm{t} \leq \frac{\pi}{2}
$$

\section{Matlab / Simulink Simulations}

Matlab / Simulink models were developed for both threephase and five-phase systems descried in section 2 . The PMGs are presented by their parameters of voltage, speed, frequency, phase resistance, and self and mutual inductance. Both simulated generators are connected with diode rectifier circuits as shown in Figure 1.

The simulations which were carried out for given output power and speed show that the performance of the fivephase system is superior in terms of shaft torque ripple and the capacitor rms current ripple. Figures 4 and 5 show the significant reduction in ripple torque (19 times) and smoothing capacitor current (9 times) respectively when using 5-phase systems compared with 3-phase counterpart. Simulations results in figure 4 show that the peak-to-peak ripple torque in the three-phase system is $2.08 \mathrm{Nm}$, while it is only $0.11 \mathrm{Nm}$ for the equivalent fivephase system. This will reduce losses and makes the fivephase generator superior in terms of output power and efficiency. In addition, reducing the level of vibrations will increase the reliability and lifetime of the generator. Simulation results shown in figure 5 show that the peakto-peak capacitor current in the three-phase system is 3.39 amps compared to only 0.29 amps for the five-phase system. As a result, it will be possible to reduce the size of capacitors in five-phase systems and consequently reduce cost where capacitor current has direct relationship with the capacitor size and cost. These significant results of the five-phase system will help to design cheaper, more efficient, compact and reliable systems for a wide range of applications including wind turbine generators.

However, it is necessary to remember that dc link capacitors are often used for two reasons: to reduce voltage ripple and to provide energy storage to enable continuous operation if the generator power reduces momentarily. Using a 5-phase machine will not reduce the energy storage requirements, but it will help in reducing voltage ripple.

Five-phase systems also demonstrate improved tolerance to failure as shown in the test results of figure 6 and this is a unique selling point of this technology. For example, when one phase of the generator or the diode rectifier circuit fails, the five-phase system is still capable of providing an output power/torque of around $80 \%$ of rated power/torque. This is significantly better than the equivalent three-phase generator which is capable of providing only around $60 \%$ of rated power/torque under the same failure conditions.

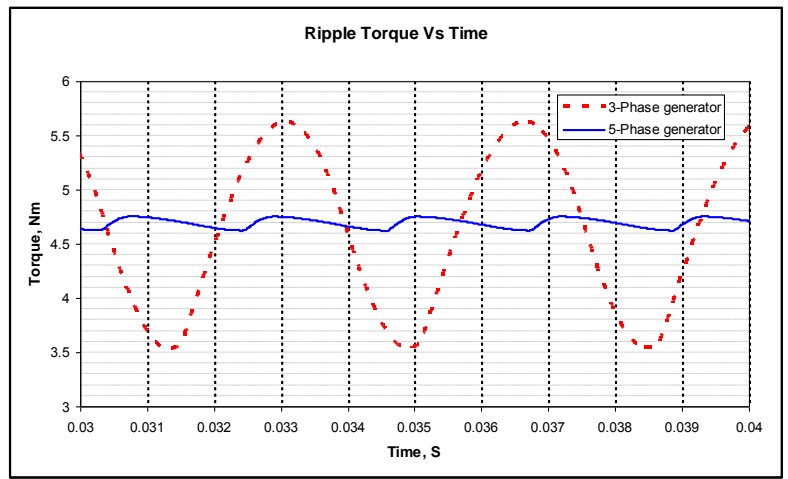

Figure 4: Simulation results of ripple torque of three-phase and five-phase systems.

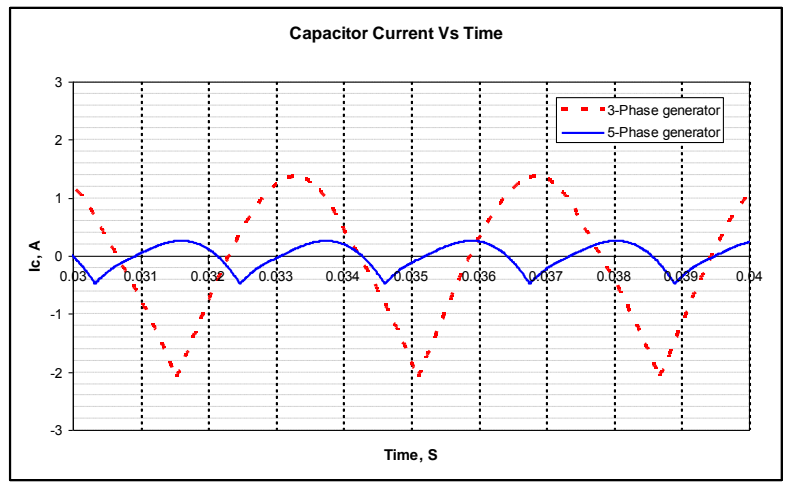

Figure 5: Simulation results of capacitor current of three-phase and five-phase systems. 


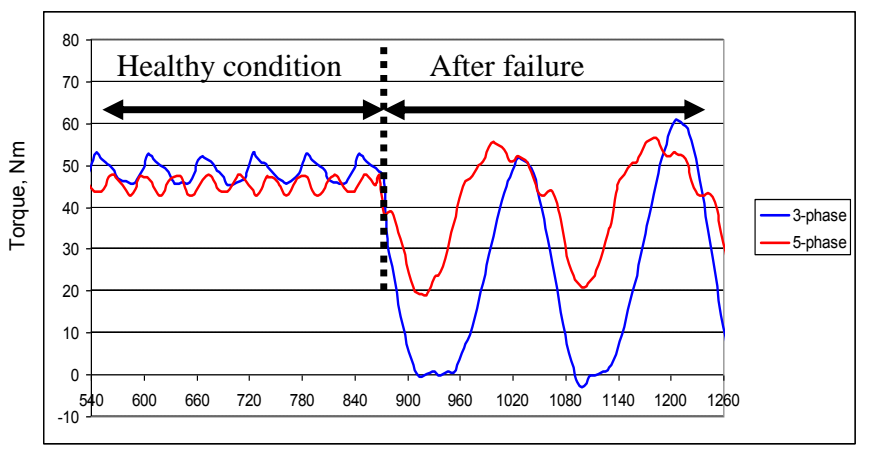

Position, Mech. degrees

Figure 6: Simulation torque results of phase fault tolerance of three-phase and five-phase systems.

\section{Test Apparatus and Results}

A test rig was developed to test the two generator systems described in section 2. A schematic diagram of the test apparatus is shown in figure 7 . The wiring of the test rig can easily be changed to suit the three-phase system tests.

The effect of single-phase failure on the output dc voltage at the dc link side was investigated. The output DC voltages shown in figure 8 are obtained from both simulations and tests of the five-phase system in normal and single-phase failure conditions. The figure also shows a good mach between simulations and test results. Figure 9 shows output DC voltage test results of three and five phase systems in normal and single-phase failure conditions. When one phase of the generator or the diode rectifier circuit fails, the five-phase system is still capable of providing an output dc voltage of around 93\% of rated output voltage at the dc link side. This is also significantly better than the equivalent three-phase generator which is capable of providing only around $85 \%$ of rated output voltage under the same failure conditions.

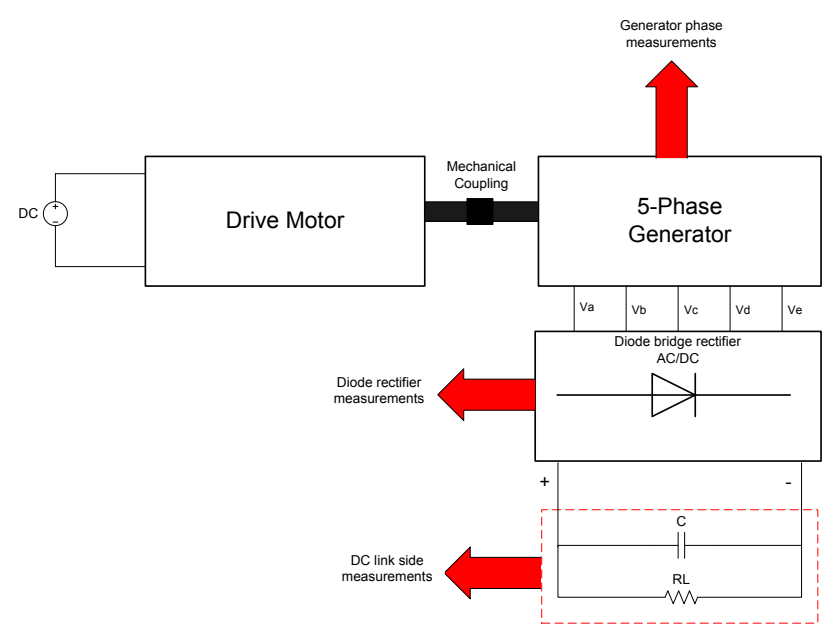

Figure: 7: Schematic diagram of the test rig.

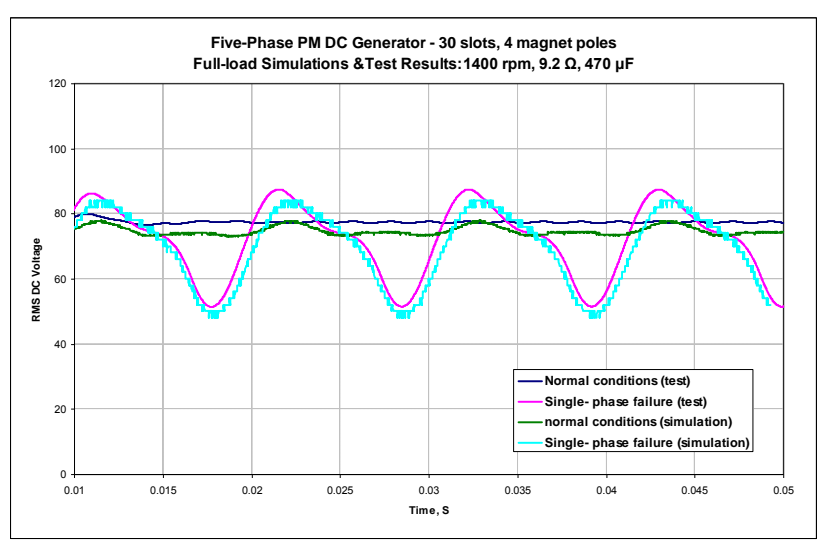

Figure 8: Five-phase DC link voltage in normal and single phase failure conditions.

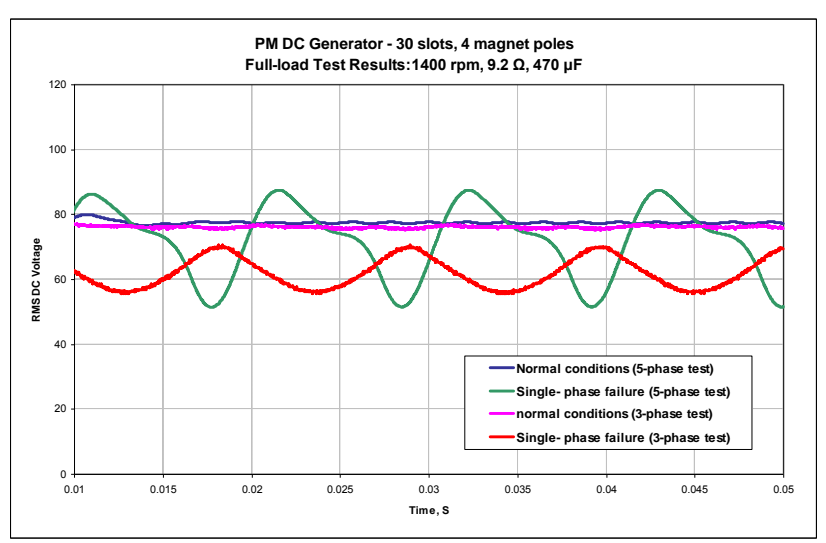

Figure 9: Test results of 3-phase and 5-phase DC voltages in different conditions

\section{Our Novel Wind-Turbine Generator}

The positive results presented on sections 4 and 5 were motivation to design a small permanent magnet dc wind turbine generator for the growing renewable energy market. The new generator is expected to replace an existing three-phase wind turbine generator that has the same power and speed rating. In addition, the new design is more compact as a result of reducing size and weight and it takes advantage of the key benefits of five-phase technology. The generator will be used with a full-bridge five-phase rectifier circuit similar to the one shown in figure 1.

Our 280mm diameter generator has 20 stator slots and 16 magnet poles and it was designed to deliver $2.5 \mathrm{~kW}$ at 300 rpm. It has been designed to deliver 500 volts (peak nonadjacent line voltage) at the dc link side at rated speed and full load. The ratio of stator slots to the magnet poles was better optimised to suit the five-phase technology. The generator also has fractional slots with double-layer windings. A cross-section of the generator shows distribution of flux lines is shown in figure 10 .

The basic and sizing design calculations of the generator have been performed using design software that has been developed at Strathclyde University. Furthermore, system analysis using $\mathrm{FE}$ has been performed for further investigations and to refine the design to improve performance and reduce size. Figure 11 shows the back 
emf waveform at 300rpm as obtained from FE at no-load. However, the generator is expected to be fully tested later this year; a test rig is under construction at the time of writing this paper.

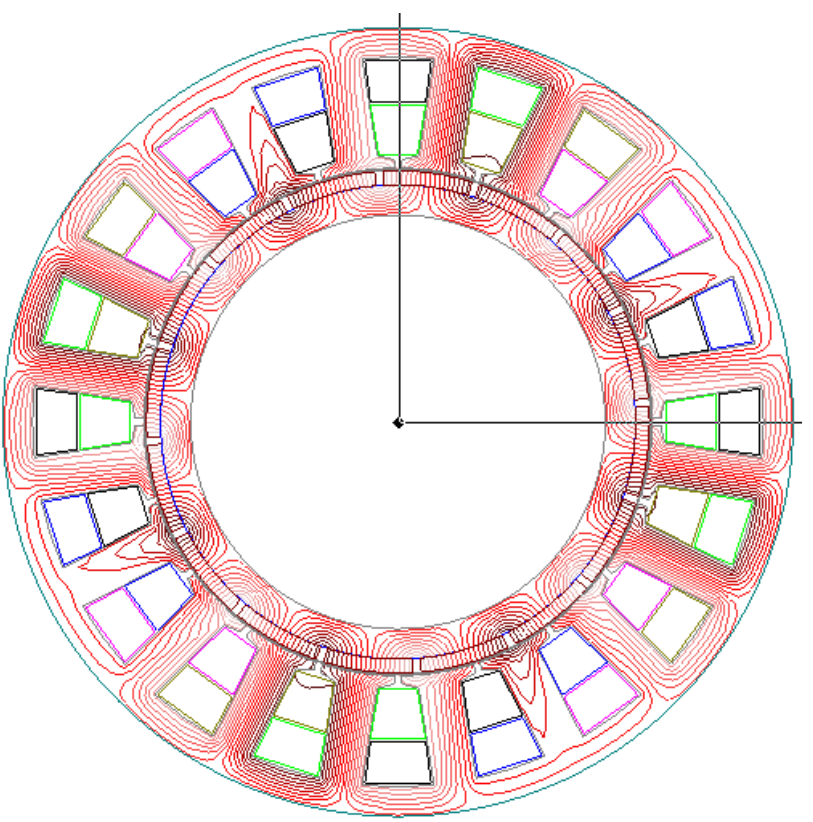

Figure 10: FE analysis shows flux distribution in a cross-section of the generator.

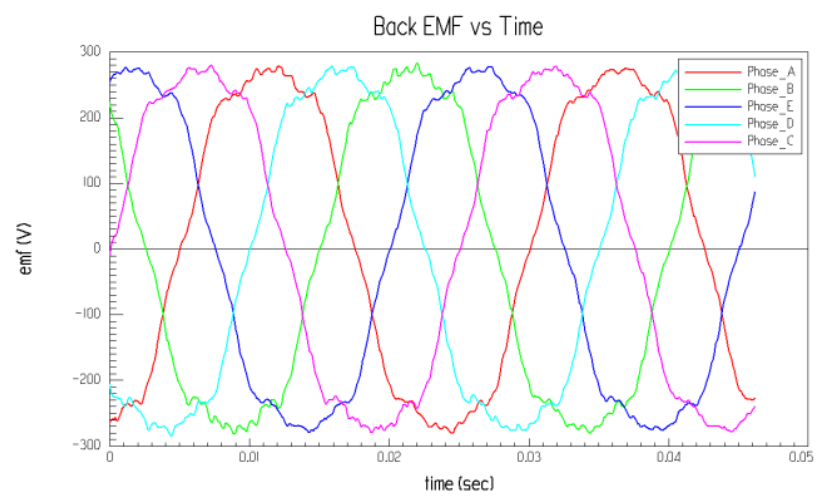

Figure 11: Transient FE analysis shows back emf at no-load.

\section{Conclusions}

Analysis of three-phase and five-phase machines demonstrating operation with diode rectifiers has been compared to demonstrate the benefits of five-phase technology for the renewable energy sector. The benefits of using five-phase systems in wind turbine applications have been investigated using Matlab / Simulink and FE and validated by test results where possible. The key two advantages of the five-phase systems over the traditional 3 -phase systems are the reduction in ripple torque and the capacitor requirements and consequently it would be possible to design cheaper, lighter, and more efficient, compact and reliable machines. A more compact fivephase wind turbine generator was designed to harness the benefits mentioned above where vibration, fatigue, and reliability are significant challenges to the industry. This generator is expected to replace a similar existing three- phase generator in a device manufactured by a worldleading wind turbine producer.

\section{Acknowledgement}

The authors would like to thank Scottish Enterprise and their "Proof of Concept Programme" for funding this project through project 9-ENR-001.

\section{References}

[1] N. A. Hassanain, and J. E. Fletcher, 'Analysis three- and five-phase permanent magnet machines supplying diode bridge rectifiers for small-scale wind generators', International Conference on Power Engineering, Energy, and Electrical drives, 2007. POWERENG 2007, pp. 648-653.

[2] L. Parsa, H. Toliyat and A. Goodarzi, "Five-Phase Interior Permanent Magnet Motor with Low Torque Pulsation" IEEE Transactions on Industry Applications, Volume 43, Jan-Feb. 2007, pp. 40 - 46.

[3] L. Parsa, H. Toliyat and A. Goodarzi, "Five-Phase Interior Permanent Magnet Motor for Hybrid Electric Vehicle Application" IEEE Vehicle Power and Propulsion Conference (VPPC), Sept. 7-9, 2005, pp. 631 - 637.

[4] L. Parsa, and H. Toliyat, "Fault-Tolerant InteriorPermanent-Magnet Machines for Hybrid electric Vehicle Applications" IEEE Transactions on Vehicular Technology, Volume 56, July 2007, pp. 1546-1552

[5] J. R. Hendershot \& T. J. Miller, "Design of Brushless Permanent Magnet Motors," Magna Physics Pub. 1994

[6] C. Hanselman, "Brushless Permanent-Magnet Motor design" McGraw-Hill, 1994

[7] S. Choi, B. Lee, and N. E Prasad, 'New 24-pulse diode rectifier system for utility interface of high-power Ac motor drive', IEEE Trans. On Industrial Application, Vol. 33, No.2, March/April 1997. pp. 531-539

[8] B. Zhang, and S. D. Pekarek, 'Analysis and average value model of a source commutated 5-phase rectifier', IEEE, Power electronic Specialists conference, 35th Annual, Aachen, Germany, 2004. pp. 362-368.

[9] M. H. Rashed, 'Power electronics -devices, derives, and application', Prentice -Hall international, Inc. USA 1993.

[10] N. Mohan, T. M. Undeland, W. P. Robbins, 'Power Electronics: Converters, Applications, and Design', second edition, Wiley, 1995

[11] PhD thesis, Hassanain, N. M, "Comparison between threeand five-phase permanent magnet generators connected to a diode bridge rectifier", University of Strathclyde, UK, 2009. 